\title{
Water and sanitation human rights for stone quarry communities at Wagholi, India
}

\author{
Madeleine Jenkins \\ Returned Field Volunteer, Engineers Without Borders Australia, Melbourne \\ madeleine.jenkins@gmail.com
}

\begin{abstract}
SANTULAN is an Indian Non-Government Organisation working to provide advocacy, education and health facilitation access to basic human rights for stone quarry worker communities in India. Engineers Without Borders (EWB) volunteers were employed to work alongside SANTULAN's existing programs and to conduct research into the water and sanitation issues faced by the stone quarry communities. This case study was developed based on five communities located near the Wagholi Township. It consisted of the assessment of the existing water sources and sanitation conditions and evaluating their subsequent health risks, in order to determine whether they are a violation of human rights and whether recommendations for improvement can be developed. Information was gathered based on observation, interviews/surveys with community members and SANTULAN staff, meetings with the Gram Panchayat (Local Self-Government) and water quality testing. Overall, it was found that the stone quarry communities do not have adequate access to clean, safe and reliable drinking water provisions, nor do they have adequate sanitation. Consequently, this poses significant health, financial, environmental and social consequences for the communities. India strongly supports the right to water and sanitation and has a duty to respect, protect and fulfil these commitments. However, in the case of the stone quarry communities, these obligations are not being met. This research will provide valuable support for SANTULAN in the form of documentational evidence to feed into an advocacy based approach for improving access to safe water and sanitation for stone quarry communities.
\end{abstract}

KEYWORDS: Water and sanitation, human rights, stone quarrying, EWB and SANTULAN.

\section{INTRODUCTION}

SANTULAN is an Indian Non-Government Organisation working in advocacy, education and health facilitation access to basic human rights for the stone quarry worker communities. Stone quarry communities migrate frequently from their villages due to low income and lack of land. The daily wages provided by quarry mining work often dissuades the workers from returning to their villages. The quarry workers tend not to stay at work-site for more than 2 to 3 years as the work can be too sporadic, the present quarry closes or they are in search of a better wage.

This lack of permanency means they do not have any kind of government personal documentation and therefore are not eligible for government benefits, they are not enrolled to vote and they do not have access to ration cards from the state Government or the local councils. Additionally, the mine industry is highly unregulated and exploitation of workers is common practice including hazardous occupational health and safety risks, low wages and no job security (figure 1).
The community housing is generally located in slum settlements next to the stone quarry/crushing sites in huts covered with temporary iron or plastic sheets and walls made of loose stones. They have no basic amenities such as a reliable clean water or sanitation (figure 2).

SANTULAN has developed various initiatives for the education, organisation and empowerment of stone quarry communities including: provision of schools, education, shelter and nutrition for children, fostering women empowerment groups and developing informal stone quarry workers' organisations to advocate for workers' rights.

As part of the Engineers Without Borders volunteer placement scheme, volunteers were assigned work in parallel with SANTULAN's existing programs for approximately 12 months. This work focused on identifying the water and sanitation issues faced by the stone quarry communities. A case study was developed to assess the existing water sources and sanitation conditions and their subsequent health risks in order to determine 


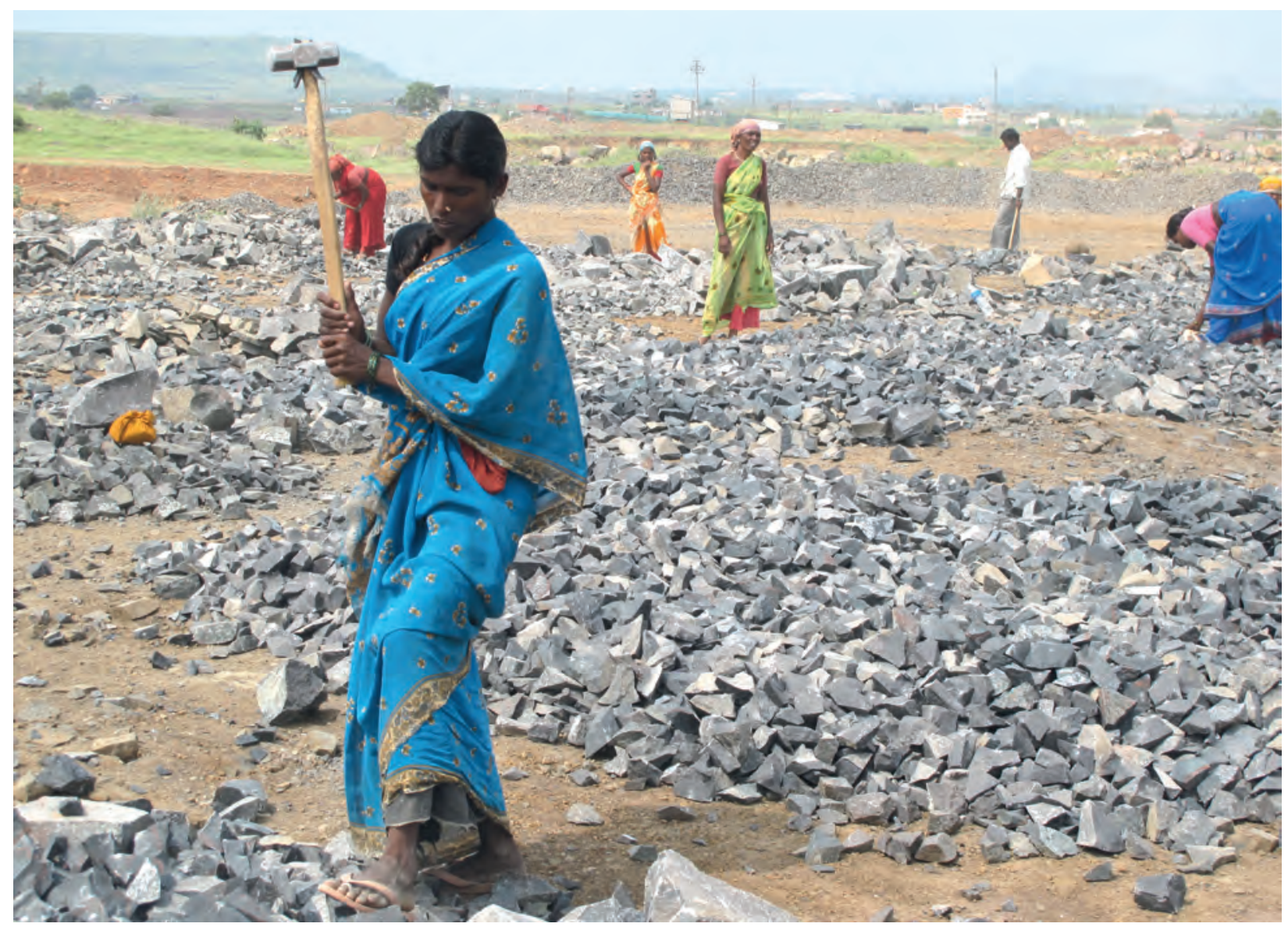

Figure 1: Working conditions on the stone quarry sites located near Wagholi Township.

whether they are a violation of human rights and where recommendations for improvement could be made. This research will provide valuable support for SANTULAN in the form of documentational evidence to feed into an advocacy based approach for improving access to safe water and sanitation for stone quarry communities.

\section{METHODOLOGY}

To fully understand the nature and extent of the water and sanitation issues, background research was undertaken which included a review of international laws and treaties, national and state policies, local plans of water infrastructure from the Gram Panchayat (local self-government) and reports on previous work undertaken by SANTULAN.

This research was based on five communities located on the quarry sites near the Wagholi Township which included: Dabhade Khanwasti (160 people), Wageshsvarnagar Khanwasti (700 people), Gorewasti (200 people), Shindewasti (200 people) and Suyog Nagar (1500 people). The communities were visited several times over the period of September 2010 until April 2011 and the current conditions of their water sources and sanitation practices were assessed based on observation, interviews/surveys with community members, meetings with the Gram Panchayat (Local Self-Government) and water quality testing undertaken in conjunction with Pune Engineering College in March 2011.

\subsection{Findings}

A particularly interesting finding for this research was that a water supply scheme was built in 2006 to service all of the communities listed above due to a successful appeal won by SANTULAN. Unfortunately, there are several issues with the water supply scheme as investigated in 2010/11. The water is supplied by the Municipal Corporation (local government body) in Pune City to the Gram Panchayat (local self-government) in Wagholi, who is responsible for distributing the water. The pumping station at Wagholi is the furthest town from Pune City being supplied and there are many illegal connections and transmission losses (Rode, 2003) in between. Therefore, the Gram Panchayat is not receiving their full entitlement to manage the distribution of the water and only possesses a significantly diminished water volume to supply the stone quarry communities.

Another issue with the existing scheme is the quality of the piping in the water distribution scheme. The piping is damaged in several locations potentially due to poor quality materials, poor construction techniques combined with the excessive loads from the stone carrying dumper trucks. Additionally, there 
are rumours that the pipes have been intentionally blocked due to caste differences and power politics. The Gram Panchayat has taken on the responsibility for operation and maintenance costs of the water supply scheme and does not charge the mining communities a user fee. Despite this, the issues of the defunct infrastructure have not been resolved. Not requesting a user fee charge may also be compounding the issue, as it is easy to discriminate against non-paying users.

The main source of drinking water for most communities is generally from wells located on neighbouring agricultural properties with access agreed upon with the local farmers. These are unprotected water sources and have varying degrees of water quality issues and require treatment to be suitable for drinking. Some people use disinfectant or boil the water but the majority of people filter the water using cloth or do not treat the water at all. Sources of pollution may include: human faeces, animal faeces, household waste, dust, sediment from erosion, fuel/oil from heavy vehicles/machines, chemicals from explosives, mineralisation, fertilisers, nitrates, phosphates from agricultural practices and pathogenic waterborne microbiological organisms.

The community of Dhabhade Khanwasti sources their water from the stone quarry pit as there are no alternative sources nearby. Community members commented that the water is not very good and has an odour. Water quality tests show high $\mathrm{pH}$, high faecal contamination and large amount of nitrates that deems the water not suitable for drinking based on the World Health Organisation drinking water guidelines. The people surveyed in this community generally do not apply any treatment methods to this water.
Aside from water supply, sanitation is also a major issue faced by the community, issues include:

- Open defecation away from the community housing is common practice and the few toilets that exist are commonly defunct. Additionally, the limited access to water means that people do not wash their hands after going to the toilet. When hand washing occurs, soap is not commonly used.

- Household waste is discarded beyond the household boundary in open fields. There is a rubbish dump at the entrance of the Wageshvarnagar community which is located on a drainage line (figure 4). This putrefying waste is provides a breeding ground for flies and rats and attracts foraging animals such as cows and pigs making it a high risk zone for infection and disease. The drainage line suffers from a significant mosquito problem as it contains muddy and stagnant water. Additionally, the waste from the Wageshvarnagar community rubbish dump is able to seep into the drainage line.

- There is a lack of stormwater drainage in all the communities. Apart from flooding during the monsoon the lack of drainage allows water to accumulate at low points in the roads creating pools of water and mud. This creates difficult access for vehicles and also a potential breeding ground for mosquitoes. Anecdotal evidence shows that there have been cases of malaria communities with such problems. The community attempts to remove the waste by burning it but the odour is foul and impacts public health as well as the environment.

- Hygiene practices are currently part of the school

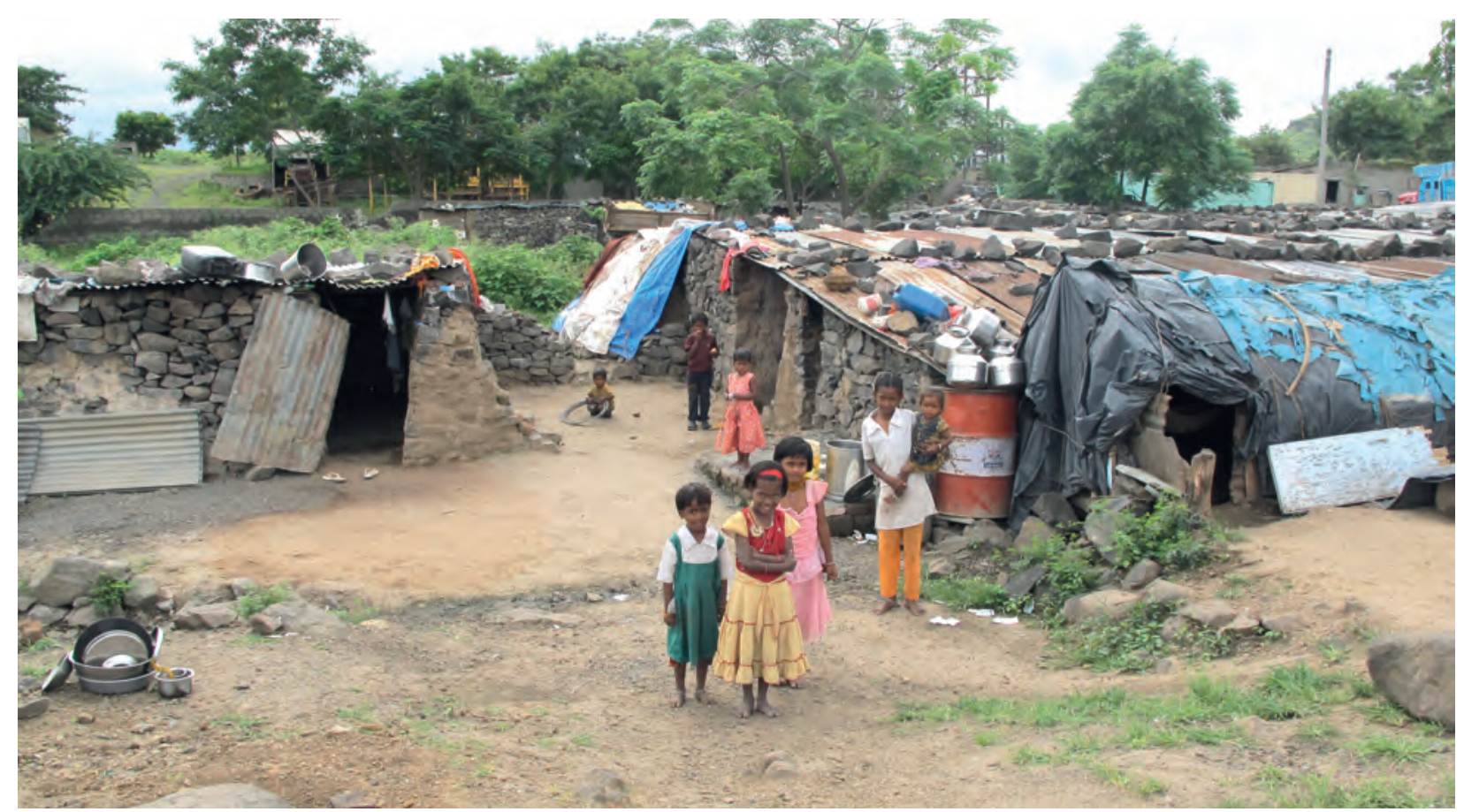

Figure 2: Typical Housing at stone quarry communities located at Shindewasti near Wagholi Township. 


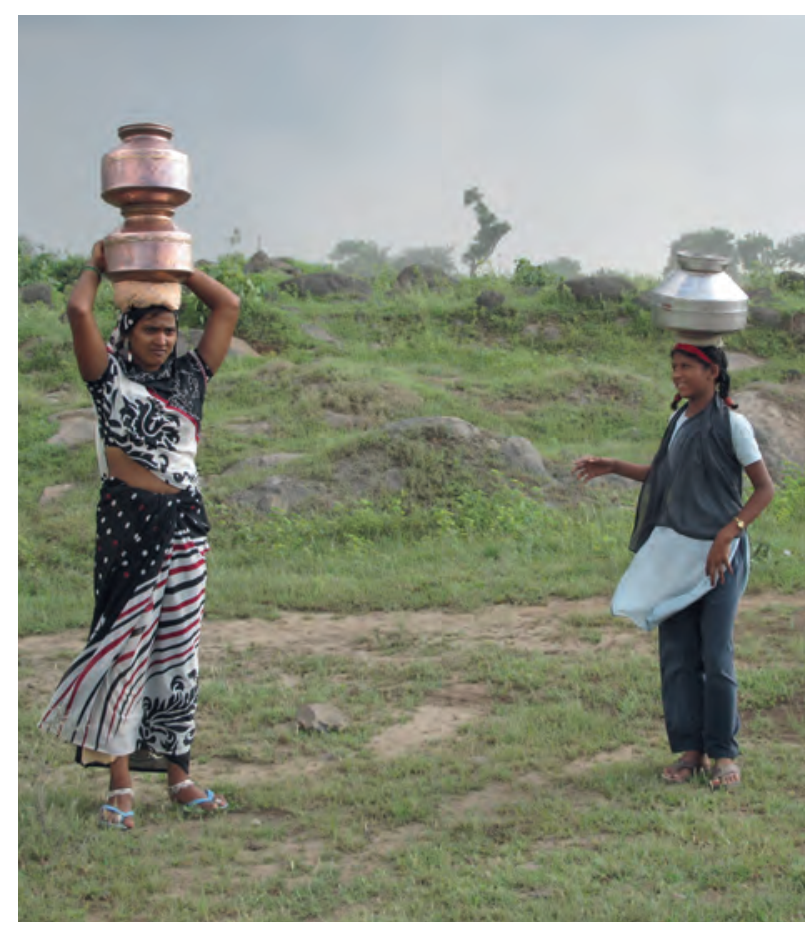

Figure 3: A woman and a school girl collecting water from a nearby well at Shindewasti.

curriculum and are followed by some of the children including: nail cutting, hand washing, bathing, combing, and wearing clean clothes. However, these practices vary between children (and also adults) and some are not so well kept.

Within each of the schools there are no drinking water or sanitation provisions. Additionally, the mine owners do not provide drinking water or sanitation facilities for employees during their shift.

There are also a number of issues are impact on the health, environment, social and financial situation of the stone quarry communities, these include:

Health Issues: Anecdotal evidence reveals that intestinal worms and diarrhoea are common health issues in the community. This can be directly attributed to poor hygienic practices, poor quality drinking water or a combination of both. Additionally, skin and eye infections are also common due to inadequate quantities of clean water for personal hygiene. There have also been cases of malaria reported within the communities indicating that the pools of stagnant water on-site encourage breeding of mosquitoes that transmit disease.

Social Issues: Women and girls are traditionally responsible for domestic water supply and sanitation and maintaining a hygienic home environment. They bear the burden of fetching water and as a result compromise their education, productive activity and leisure time.

Women also pay a heavy price for poor sanitation. The only time available for women or girls to defecate, if they do not have a latrine, is after dark.
Apart from the discomfort caused by the long wait, this can cause serious illness (UNICEF, 2008). There is also a risk of harassment and assault during the night-time walk to and from the communal defecation fields.

The lack of safe, separate and private sanitation and washing facilities in schools is a factor preventing girls from attending school, particularly while menstruating.

Financial Issues: Diseases from poor water and sanitation practices mean there is a high rate of sick days from work impacting pay and also a high rate of sick days from schools impacting the children's education.

Additionally, the community members spend their already scarce amount of money on medicine. Some families also spend money on water carting.

Environmental Issues: Lack of sanitation is polluting the environment including ground water, surface water and air quality. Drinking water sources are under increasing threat of contamination, with far reaching consequences for the health of children and for the economic and social development of the communities.

\section{EVALUATION}

What do these findings mean in terms of human rights violations and whose responsibility is it to do something about it?

The right to water is defined as follows (UN, 2010a): "The human right to water entitles everyone to sufficient, safe, acceptable, physically accessible and affordable water for personal and domestic uses." The right to sanitation is "access to, and use of, excreta and wastewater facilities and services that ensure privacy and dignity, ensuring a clean and healthy living environment for all" (The Rights to Water and Sanitation Portal, 2010).

India has repeatedly acknowledged these rights at an international level and is a State party to several documents which explicitly recognise water and sanitation as a human right, these include: the International Covenant on Economic, Social and Cultural Rights (ICESCR); Convention on the Elimination of all Forms of Discrimination Against Women (CEDAW); and Convention on the Rights of the Child (CRC).

Consequently, India has an obligation at both the national and state levels to respect, protect and fulfil these commitments. A part of these commitments includes recognising the right to water and sanitation within national legislation. Although India does not have an explicit reference to these rights in the national legislation, the Supreme Court has ruled that both water and sanitation are part of the right to life (Article 21 of the Indian Constitution). 
Based on the findings of this case study, the following obligations are not being met:

- The Municipal Corporation has failed to provide adequate water supply to Wagholi pumping station presumably due to low revenues and low levels of investment in urban infrastructure. Given that there are sufficient financial resources to address lack of access to water (not necessarily in the municipality, but at higher ranks of State), the failure to meet the State's obligation to fulfil this duty is a violation of people's right to water. As India is a State party to the (ICESCR), the Government should ensure investments in water facility access for all members of society and prioritise investment in water and sanitation services and facilities to areas that currently have low or limited access. The State is duty bound to ensure the right of access to water and water services and facilities on a nondiscriminatory basis, especially for marginalised or disadvantaged groups.

- In order to manage the reduced allocation of water, the Wagholi Gram Panchayat has significantly reduced if not ceased to provide water to the stone quarry communities. Additionally, part of the water supply system is defunct and has not been maintained by the Gram Panchayat. The quarry communities tend to be the first to miss out as they cannot afford to pay for water and they do not have any representation in the political sphere. The Gram Panchayat has plans to construct a new water supply scheme in 2011 but this does not guarantee that issues regarding discrimination will be resolved. The State has a duty to prevent the service delivery from compromising equal, affordable and physical access to sufficient, safe and acceptable water and the failure to meet the State's obligation to fulfil this duty is a violation of people's right to water.

- There is a high rate of disease attributed to poor quality drinking water from unprotected sources. The Government is duty bound to ensure drinking water meets quality standards, and provide information to all groups regarding safe water storage, hygienic sanitation and water quality to combat disease. Failure to do this is a violation of the right to water and a violation of the right to health.

- Women pay the heaviest price for poor water and sanitation. Governments should take measures to alleviate the disproportionate burden women bear in the collection of water, and ensure that children are not prevented from enjoying their human rights (such as right to education) due to time collecting water. Additionally, The State has a duty to ensure that no person is discriminated against in regard to her right to sanitation. Failure to do so is a violation of the right to water and sanitation and is discrimination against women.

- The failure to provide sanitation services such as waste collection and latrines to the stone quarry communities is a violation of the right to sanitation, a violation of the right to health and a violation of the right to a clean and

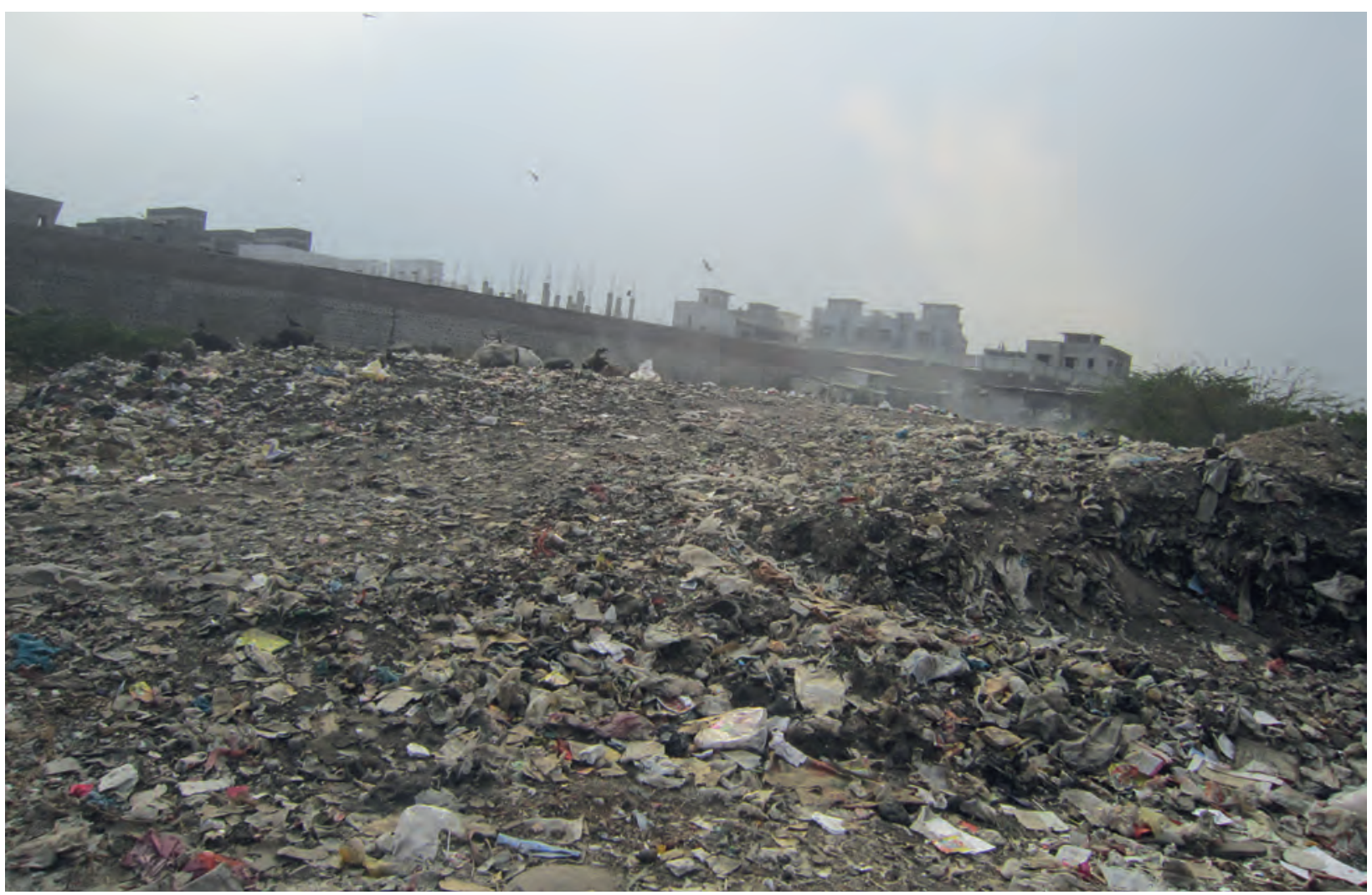

Figure 4: Uncontrolled dumping of rubbish located at the entrance of Wageshvarnagar Khanwasti. 
wholesome environment. According to the Indian Constitution the State has duty to ensure amongst others, a decent standard of life and to improve public health and sanitation. It declares a national commitment to protect and improve the environment.

- Mine owners are also duty bound to meet their obligations based on the Mines Act (1952) and the Mines Rules (1955). This includes provision of drinking water and latrines for all employees during their shift at conveniently accessible locations. Mine owners failing to meet their responsibilities are committing a violation of rights to water and sanitation.

\section{4}

\section{CONCLUSIONS AND RECOMMENDATIONS}

Through this case study, it is clear that the stone quarry communities settled near Wagholi do not have adequate access to clean, safe and reliable drinking water provisions nor do they have adequate sanitation. The information collected throughout this research is useful evidence for SANTULAN to adopt an advocacy approach directed towards the key actors causing the water and sanitation problems including the: Gram Panchayat, Municipal Corporation and the mine owners.

Demands for the Gram Panchayat should include: on-going maintenance of the entire water supply scheme to ensure continual operation, provision of a minimum of 20-50 L/person/day of water suitable for drinking, provision of water carting if there is a water shortage, representation of the stone quarry community at the next Wagholi Water and Sanitation Committee meeting, construction of at least 1 toilet per 20 people as per minimum standards for each community and implementation and maintenance of storm-water drainage systems.

Demands for the Municipal Corporation should include weekly waste collection from the Wagholi quarry site.

Demands for the mine owners should include provision of at least $2 \mathrm{~L}$ per person per shift and the provision of at least 1 toilet per person at conveniently accessible places on the mine site, in accordance with 'The Mines Rules (1955)'.

Additionally, an advocacy campaign should be complemented by work with the community to raise awareness of their rights and promote water, sanitation and hygiene practices. Each school should also include toilets, washbasins and drinking water provisions as per requirements of 'The Right to Free and Compulsory Education Act, 2010'. With funding support, SANTULAN has the capacity to undertake these activities.

\section{ACKNOWLEDGEMENTS}

I would like to thank the professors and students from Pune Engineering College who enthusiastically assisted with collecting and testing water samples. Thanks also to the team of support at EWB and most importantly thanks to SANTULAN for the selfless dedication to such a noble cause that is making a difference in the world.

\section{REFERENCES}

FanGlobal, 2010 Rights to Water and Sanitation - A Handbook for Activists. Available at: http://www. wash-united.org/media/club-news/club-news / article / $/$ the-rights-t.html?no_cache $=1$

Government of India, 1952. The Mines Act (1952). Available at: http://coal.nic.in/weboflifeminessafety/ma_1952.pdf

Government of India, 1955. The Mines Rules (1955). Available at: http://coal.nic.in/weboflifeminessafety/mr.pdf

Government of India, 2009. The Right to Free and Compulsory Education Act, 2010.

Office of the United Nations High Commissioner for Human Rights, 2010a. International Covenant on Economic, Social and Cultural Rights 1966. Available at: http://www2.ohchr.org/english/law /

Office of the United Nations High Commissioner for Human Rights, 2010b. Convention on the Elimination of All Forms of Discrimination against Women. Available at: http:/ / www2.ohchr.org/english/law/

Office of the United Nations High Commissioner for Human Rights, 2010c. Convention on Rights of the Child. Available at: http://www2.ohchr.org/english/law/

The Rights to Water and Sanitation Portal, 2010. Available at: http://www.righttowater.info/ progress-so-far/timeline/

Rode, Sanjay, 2003, Sustainable Drinking Water Supply in Pune Metropolitan region: Alternative Policies from Centre for Development Alternatives, Ahmadabad, Gujarat. Available at: http://um.ase.ro/no1S/5.pdf

Santulan, 2009. Movement towards Rights and Livelihood of Informal - Migrant Stone Quarry Workers in Maharashtra, India.

UNICEF, 2008. Water, Sanitation and Hygiene. Available at: http://www.unicef.org/wash/index_ hygiene.html 